been an arduous worker at this branch of science, and it will be convenient to have in a compact form the outcome of his numerous fuller publications, which it is the object of this book to present. Prof. Loeb's name is best known in connection with th.e parthenogenesis which he has artificially produced in unfertilised marine eggs, by altering the saline constituents and other physical conditions of the surrounding water. This subject is here given in its most recent developments, but the book naturally contains a good deal in addition. We may regard the work as a useful counterblast to those who term themselves neo-vitalists. It can hardly be considered the last word on the subject. Physical chemistry in relation to inorganic material is in a state of flux, one theory displacing others with startling rapidity. It is, therefore, a little early to apply it to organic and living substances with any hope of obtaining universal acceptance of the theories put forward. The speculations indulged in are interesting, and the facts will settle down into their proper places later on.

The third book in this physiological batch relates to a small corner of physiological inquiry, namely, taste and smell, and mainly the former. Dr. Sternberg has devoted attention to this sub-branch of a branch of physiology, and has produced a readable pamphlet. It is, however, a little difficult to understand why books should be written with such limited scope, and it is doubtful if they are really needed.

\section{MATTER AND RADIO-ACTIVITY.}

The Electrical Nature of Matter and Radio-activity. By Prof. Harry C. Jones. Pp. ix +212 . (London : Archibald Constable and Co., Ltd., I906.) Price 7s. $6 d$. net.

THIS book consists of a series of articles, written 1 in semi-popular style, reprinted from the Electrical Review. The first third of the book is occupied with the electronic theory of matter, and follows the usual popular lines. The subject is treated only from what may be called the Cavendish Laboratory point of view, and, in fact, we read that we owe the whole electronic conception to Prof. J. J. Thomson. The optical and spectroscopic foundations for the theory are omitted, and the names of Larmor, H. A. Lorentz, and Zeeman are not mentioned.

It is difficult to attempt to review this part of the book, for if the reviewer has interpreted a recent paper by Prof. J. J. Thomson aright, the view that the constituent electrons of an atom are present in sufficient numbers to contribute any appreciable part of its mass appears to have been disproved. Here, however, we read:-

"There is one point at least brought out so clearly that there can scarcely be any question about it, and that is that matter is a pure hypothesis."

And again :-

"The atom according to this theory is very complex. Take, for example, the atom of mercury. No. 1930, VOL. 74]
This contains somewhat more than 150 ,ooo electrons, and some of the heavier atoms are even more complex."

The author, by thus presenting so dogmatically and literally the speculations which have centred around the electron as the basis of matter, has directed attention away from the solid experimental work on which our knowledge of the nature of electrons rests. It is this work, and not the sweeping electronic hypothesis, which is connected with radioactivity. But for the pioneer work on the ionisation of gases done in the Cavendish Laboratory and elsewhere, the electrical method of radio-active measurement could not have reached its present perfection, and it is safe to say that, deprived of this method, radio-activity would have advanced but slowly. But whether the atom of mercury has 200 or ${ }_{5} 50,000$ electrons is a question which fortunately has nothing to do with the very fundamental and independent conclusions of the nature of matter formed from radio-active evidence.

Radio-activity, the second topic, is started in chapter v., and with the remainder of the work and the mode of treatment no exception can be taken, except that it is not very up-to-date. The last chapter, which is entitled "Most Recent Work in Radio-activity," attempts, however, to accomplish this.

The book as a whole gives a comprehensive and interesting survey of the radio-activity of matter as it is interpreted by the disintegration hypothesis. Perhaps the best chapters are those dealing with the reproduction of radio-active matter and the theory arising therefrom. Here the chemical training and point of view of the author are in evidence, and the significance of the continuous reappearance of the products of change after complete removal by chemical or other means is very clearly brought out.

Attention may be directed to some inaccuracies and errors of minor importance. The author does not seem very clear about the nature and properties of the $\gamma$ rays. We learn that their power to affect the photographic plate is much greater than that of the $\beta$ or even the $\alpha$ particles, an error which is frequently repeated. Their origin is ascribed to the impact of $\beta$ rays on solid matter rather than to the acceleration of the $\beta$ particle during expulsion. In the experiment of causing, by means of a glass tube containing radium, a discharge to pass between two points just so far apart that ordinarily the spark fails, most of the ionisation from the glass tube is ascribed to the $\gamma$ rays. It is safe to say that if the glass were as thick as this the experiment would fail. The statement that the emanation can be condensed at low temperatures like an ordinary gas into a liquid is obviously a slip, for a little later we read that no liquid or even mist will be seen. Twice later, however, the statement is repeated, and liquid appears a loose word for non-gaseous. The $\beta$ rays are ascribed little power of exciting phosphorescence, and the effect on a platino-cyanide screen is said to be greater for $\alpha$ than for $\beta$ and $\gamma$ rays.

F. S. 